\title{
Pandemia, engajamento sanitário, desajuste social e necrofilia presidencial
}

\section{Pandemic, health engagement, social misfit and presidential necrophilia}

\section{Renato Nunes Bittencourt ${ }^{*}$}

Resumo: O artigo aborda a calamidade pandêmica da COVID-19 a partir de um enfoque que conecta perspectivas filosóficas, políticas e econômicas na compreensão desse caos global. Disposições éticas são analisadas na tentativa de se mitigar os efeitos deletérios da pandemia na vida humana, assim como os fatores governamentais e corporativos que impedem maior capacidade de enfrentamento da COVID-19, para maior prejuízo da humanidade.

Palavras-chave: Pandemia; Vida; Ciência; Economia; Sofrimento

Abstract: This article approaches the pandemic calamitv due to COVID-10 through a focus that connect philosophical, political and economic perspectives in this global chaos comprehension. In an attempt to decrease the pandemic deleterious effects in the human life. ethical arrangements are analvzed. as well as corporative and governmental factors that impede the fight capacity against COVID-19 and increase the humanity loss.

Keywords: Pandemic; Life; Science; Economy; Suffering

Se a natureza já não tivesse inventado os vírus, nós próprios seríamos forçados a inventá-los ${ }^{1}$

\section{Introdução}

Um mundo em crise exige um empreendimento global para a tentativa de solucionar os problemas que o afligem, sem que tenhamos garantias de resolução dessa situação. Toda estabilidade ansiada em nossa vida moderna nunca se realiza satisfatoriamente, e os efeitos das contingências ambientais solapam as mais nobres pretensões civilizacionais. Não apenas as guerras calcaram a trajetória histórica da humanidade, mas também os efeitos das pestes devastadoras. Com efeito, pela pandemia da COVID-19 estamos em mais um momento decisório. Depositamos nossa confiança na excelência científica, nas habilidades dos médicos, enfermeiros e demais profissionais da saúde para que os danos pandêmicos sejam mitigados. Contudo, as ações governamentais são decisivas para o enfrentamento eficaz desse grande mal global, e por isso exigem fiscalização contínua da esfera pública para que a mão do Estado atue em prol do bem comum.

Diante de uma pandemia, qual a contribuição que os filósofos e demais intelectuais podem proporcionar para o mundo? Nosso papel é ínfimo nessa questão, mas podemos analisar as relações de forças que se encontram subjacentes nas políticas epidemiológicas aplicadas para se combater a COVID-19 e desmistificar os interesses corporativos,

\footnotetext{
${ }^{1}$ DYSON, O Sol, o Genoma e a Internet, 36.
}

Doutor em Filosofia pela Universidade Federal do Rio de Janeiro, Rio de Janeiro, RJ. E-mail: renatonunesbittencourt@gmail.com ORCID: https://orcid.org/oooo-0002-4492-5545 
partidários, econômicos e ideológicos ocultos no seio da sociedade e nas relações internacionais. Nada de humano nos é alheio. A erupção de uma pandemia aflora tanto as boas como as más disposições humanas, e assim temos um grande terreno ético-moral a ser investigado. Não nos esqueçamos também da necessidade de analisarmos as metodologias científicas, seus postulados e critérios de validação, pois os riscos humanitários decorrentes da substituição da razão e da técnica pelas superstições obscurantistas, pelas ideologias necrófilas, pela desinformação social, pela legitimação insalubre da ignorância são efetivos atentados contra a vida e que fazem barreira contra os esforços sanitários na diminuição da curva pandêmica. Destaque-se ainda que o cenário global de medo, desolação, luto, expectativa, ansiedade, potencializadas pela necessidade imperiosa de cumprimento de isolamento social, inevitavelmente estimula reflexões ontológicas acerca da condição humana, nossa finitude e miserabilidade perante os riscos cotidianos de contaminação, adoecimento e morte pela COVID-19.

\section{A era pandêmica e o embate entre o lucro e as pessoas}

Diferentemente da peste bubônica, da febre amarela, da hanseníase ou da varíola, doenças que demonstram de forma bruta os seus sinais como estigmas na carne dos infectados, a COVID-19 é uma doença "invisível”. Talvez a ausência de sintomas visualmente chocantes impeça aos segmentos ignorantes da sociedade a adoção de maiores cautelas profiláticas, recalcitrando-se em posturas estúpidas e temerárias (cabe ressaltar que com a anuência do grande energúmeno adornado com a faixa presidencial). Esse fato, além da demora em se diagnosticar a COVID-19 talvez gere no imaginário popular a falsa crença de que é uma doença que não acarrete maiores problemas para o enfermo. $\mathrm{O}$ alto índice de letalidade desmistifica, a passos lentos, esse mito espúrio.

Por diversos fatores alheios aos bem comum, inúmeros governos nacionais camuflaram os problemas reais da difusão pandêmica da COVID-19, defendendo a preservação da normalidade da vida cotidiana para os seus cidadãos, sem qualquer restrição de circulação social. O turismo, a produção e os negócios são colocados acima das necessidades humanas fundamentais, pois o lucro é o foco maior da agenda política controlada pela lógica do mercado. Os resultados deletérios dessa irresponsabilidade política não tardaram a se manifestar: contaminação massiva da população, taxa de mortalidade se ampliando em proporção geométrica, colapso dos hospitais, falta de equipamentos médicos, exaustão dos abnegados profissionais de saúde, histeria coletiva, profusão de teorias esquizoides para justificar tamanha miséria pandêmica. Para agravar a situação, a pandemia fortaleceu, entre os países mais afetados por ela, uma insana guerra comercial desprovida de qualquer comprometimento diplomático internacional. Quem paga mais leva o produto necessário para abastecer seu sistema de saúde, em prejuízo daqueles que ofertaram originalmente valor menor.

Alguns governos determinam que os protocolos médicos, em caso de escassez de recursos, priorizem os pacientes jovens em relação aos idosos, em uma clara política eugenista que satisfaz com muito gosto os interesses previdenciários, ou seja, gerontofobia institucionalizada para economizar recursos públicos. A injustiça contra os idosos é ainda mais cabal se levarmos em consideração o longo tempo de contribuição dessas pessoas para a coisa pública, seja pelo trabalho realizado que tanto beneficiou estruturação da sociedade, seja pelo pagamento de impostos, seja até mesmo pelos atos de consumo que movimentam a economia, mas acima de tudo pelo fato de que são cidadãos membros da sociedade e, como tais, dignos de todos os direitos constitucionais. Descartar os idosos por um critério 
utilitarista é assim logicamente e moralmente injusto. Cabe ainda destacar que preterir pessoas de uma determinada faixa etária em favor de outra não é uma garantia absoluta de salvação para o grupo eleito. Imaginemos a seguinte situação: na falta de recursos hospitalares, em uma tomada de decisão extrema, é mister que se escolha entre um jovem, pobre, e um idoso, rico. Quem será o selecionado para receber os devidos atendimentos? Acreditamos que os profissionais de saúde seguirão o critério técnico-deontológico estabelecido, que é o de preservar a vida mais jovem. No entanto, em nossa sociedade plutocrática o a decisão final certamente seguirá parâmetros econômicos, e quem sabe uma ordem anódina determine a preservação da vida do idoso rico, muito bem relacionado com os altos círculos do poder. Nesses termos, o jovem é útil apenas quando sua família é dos altos estratos sociais. Não seria então de se estranhar se o fascismo de mercado incrustado em governos ultraliberais determinasse também que as massas economicamente inviáveis, os pobres, os favelados, os sem-teto, fossem relegados ao esquecimento sanitário. De certa forma isso já é realizado de forma indireta por essa gestão necropolítica ao diminuir investimentos na infraestrutura social, degradar os serviços de saúde pública, gerenciar pessimamente os sistemas de transporte e impedir uma efetiva reforma habitacional. É a base da pirâmide social quem mais sofre dos efeitos mortais da pandemia, para maior regozijo dos plutocratas. Portanto, a discussão qual faixa etária seria priorizada em caso de escassez de recursos escamoteia a grande questão, ou seja, a divisão de classes sociais, o hiato entre a elite e os pobres. Como pessoas que dormem ao relento ou que habitam em casas precárias conseguirão seguir as medidas sanitárias adequadas? Para piorar a nossa distopia pandêmica, algumas lideranças europeias ousaram propor que testes de vacinas para cura da COVID-19 sejam realizados em africanos, reafirmando o espírito colonialista e imperialista que perpassa a ideologia da mítica superioridade racial e cultural dos países europeus em relação aos ditos "bárbaros" e "subdesenvolvidos". Nada mais do que um nazismo reconfigurado em nossa modernidade cada vez mais liquefeita.

As divulgações epidemiológicas repetem constantemente que idosos, pessoas com problemas respiratórios, hipertensos e diabéticos fazem parte do grupo de risco da COVID19, e não podemos duvidar que as seguradoras de saúde saibam explorar torpemente tal situação para aumentar o valor das apólices dos indivíduos que se enquadram nessas categorias. No entanto, os fatos comprovam que pessoas com "histórico de atleta" também sucumbem aos efeitos da doença. Nessas condições, ninguém pode então se considerar livre de ser contaminado pelo coronavírus. Recém-nascidos e anciões morrem de COVID-19, os dois extremos da temporalidade da vida humana. De um lado um bebê que sequer pôde desenvolver seu potencial, de outro lado uma pessoa longeva que passou por tantas adversidades, mas não resistiu ao poder do coronavírus.

A humanidade está dividida entre os sintomáticos e os assintomáticos que, caso não adotem medidas restritivas convenientes, se tornam os portadores ambulantes da virulência, daí a importância de se refrear a circulação pessoal nos espaços públicos. O isolamento social é estabelecido como uma política de saúde pública não apenas para que se consiga mais tempo para equipar os hospitais com os recursos imprescindíveis para se combater a pandemia, mas também para que a sua curva de contágio possa diminuir. Mais pessoas andando pelas ruas sem as devidas precauções higiênicas e sem os aparatos necessários (uso de máscara) só aumenta a probabilidade de contágio massivo, circunstância sempre destacada pelas genuínas autoridades epidemiológicas.

A COVID-19, tal como outras pandemias do passado, não é uma punição divina para expiar os pecados da humanidade, tal como interpretações escatológicas, fundamentalistas e irracionalistas apregoam orgulhosamente para melhor desonrar a memória dos mortos e a dignidade dos vivos. As hipóteses pseudocientíficas mais absurdas são criadas para que se 
legitime ideologicamente a devastação social produzida pela letalidade da pandemia. Norbert Elias salienta que

Quando as pessoas carecem de um conhecimento seguro da realidade, também ficam menos seguras; exaltam-se com maior facilidade, entram mais rapidamente em pânico; preenchem as lacunas de seu conhecimento realista com conhecimento fantasiosos e buscam aplacar o medo de ameaças inexplicáveis por meios igualmente fantasiosos ${ }^{2}$.

No caso brasileiro, até mesmo os excessos lúbricos do Carnaval foram responsabilizados como uma das causas da "ira divina" que se abateu sobre o povo através da COVID-19 como punição por seus pecados. Esse tipo de posicionamento simplista e moralmente degenerescente é utilizado, sub-repticiamente, para justificar o baixo empenho de lideranças governamentais desprovidas da laicidade política. Na ausência da razão, o vírus da indigência intelectual prolifera vorazmente. Conforme argumenta Susan Sontag,

Os pacientes que estão sendo instruídos no sentido de que, involuntariamente, causaram sua própria doença, também estão sendo levados a sentir que eles a mereceram [...]. Nada é mais punitivo do que atribuir um significado a uma doença quando esse significado é invariavelmente moralista. Qualquer moléstia importante cuja causa é obscura e cujo tratamento é ineficaz tende a ser sobrecarregada de significações ${ }^{3}$.

Há forças naturais que, apesar de toda nossa longa trajetória técnica e nossos avanços medicinais, permanecem incontroláveis, e assim nos encontramos perante desafios epidemiológicos novos que demandam racionalidade, metodologia científica, planejamento, eficiência, gerenciamento de recursos e senso republicano na gestão social. Discursos demagógicos de líderes populistas desprovidos de tecnicidade e de veracidade, verborragias religiosas de fanáticos e outras bizarrices negacionistas não merecem qualquer credibilidade, apesar dos efeitos negativos gerados por essas emissões odiosas em segmentos ignorantes do tecido social, que aceitam essas sandices como se fossem revelações divinas inquestionáveis, revelações essas que são propagadas pelos novos canais da difusão das mensagens divinas, as redes sociais e os aplicativos. Uma justa punição para essa súcia de criminosos que atentam contra a razão pública seria enviá-los para um campo de reeducação, para que talvez pudessem posteriormente tornar-se verdadeiramente úteis para a sociedade. $\mathrm{O}$ mesmo destino se aplicaria para os setores do mercado, empresários, investidores e comerciantes que encontram na pandemia um filão lucrativo para os seus negócios. Produtos para assepsia e higiene pessoal, gêneros alimentícios, remédios sofreram elevação de preços na explosão da COVID-19. O discurso ultraliberal alega que isso é resultado do aumento da demanda em relação à oferta. Como a morte é altamente lucrativa para o mercado necrófilo, talvez os preços dos caixões e das sepulturas também sejam elevados consideravelmente. $\mathrm{O}$ capitalismo é assim um regime que sempre se reinventa, independentemente da dignidade da vida humana. Tzvetan Todorov salienta que "Não sendo indivíduos dotados de uma consciência, as empresas não sentem nenhum remorso por se deixarem guiar unicamente pela busca de lucro. A limitação desse apetite só pode provir de uma instância externa à lógica econômica" 4

\footnotetext{
${ }^{2}$ ELIAS, A solidão dos moribundos, 87-88.

${ }^{3}$ SONTAG, $A$ doença como metáfora, $73,76$.

4 TODOROV, Os inimigos íntimos da Democracia, 108.
} 
Acreditar que o capitalismo estará superado após o colapso da COVID-19 e o processo de reconstrução global da sociedade é um tanto irreal. As grandes corporações multinacionais, os bancos e a estrutura plutocrática hegemônica do mundo sofrem alguns revezes imediatos, mas graças ao apoio financeiro dos governos (seus representantes reais), essas forças elitistas conseguem se recompor. Concentração de riquezas, desigualdades sociais e falta de serviços públicos se acentuaram na pandemia, situação que exige uma mudança de direcionamento da ordem sociopolítica internacional. O desastre sanitáriohumanitário da COVID-19 exigiu do Estado, em sociedades democraticamente mais avançadas, um papel interventor na economia para a manutenção da ordem pública, tal como um grande esforço de reconstrução social pós-guerra. É importante destacar esse fato pois no Brasil, apesar de nosso formalismo democrático e apregoada "solidez das instituições", não estamos em uma efetiva democracia substantiva, uma vez que a presidência nacional e grandes segmentos dos três poderes gerenciam suas pautas por critérios contrários ao fortalecimento da coisa pública, em uma promíscua relação entre fascismo, plutocracia e fundamentalismo "cristão", gerando assim um proposital caos institucional. Por isso a morosidade governamental em prover os recursos necessários para sanar os efeitos dos males da COVID-19 na sociedade brasileira, ao mesmo tempo em que o presidente acéfalo, em seus arroubos de demonstração espetacular de falsa masculinidade, não hesita em transitar entre populares sem qualquer distanciamento social e sem a adoção das medidas higiênicas, além de constantemente sabotar os empreendimentos epidemiológicos com a exibição de sua estupidez.

Apesar de visar, de modo geral, a preservação das condições mínimas da população, não ocorre nesse processo intervencionista (inclusive chancelado pelo FMI, o que comprova os limites econômicos e políticos do ultraliberalismo) a superação do modo de produção capitalista. Tudo é operacionalizado para manter a velha ordem econômica. Talvez se dê maior importância para as pesquisas científicas, aumento dos investimentos em infraestrutura social, aprimoramento de hospitais, melhor planejamento e execução de obras de saneamento básico, estabelecimento de uma renda mínima universal, uma série de concessões positivas para o bem-estar dos cidadãos, é claro, mas para que no fundo tudo se mantenha tal como está. Qualquer outro exercício futurológico é temerário. Uma revolução política somente ocorre quando os tensionamentos sociais e as contradições estruturais alcançam um tal nível de irresolução que a luta popular é a única solução para vencer a ordem vigente, levando-se em consideração a capacidade de mobilização das massas em torno de um projeto social em que o establishment é dissolvido e substituído por uma governança que coloque a efetivação do bem comum na ordem do dia.

\section{A ética do isolamento social}

Permanecer em rigoroso estado de isolamento social não é a negação da política, mas, na verdade, a sua própria afirmação. A prédica epidemiológica de se ficar em casa ou se evitar ao máximo descumprir essa recomendação técnica demanda grande senso republicano no sujeito sitiado. Os cuidados assépticos, analisados objetivamente, não são exigências de etiqueta e a efetivação de um comportamento civilizado, mas o cumprimento de um grande dever moral para com a sociedade. A higiene corporal é o exercício da salvação pessoal. O sabão e o álcool em gel são as substâncias sagradas para a limpeza das mãos, e o uso das máscaras expressa uma nova estética, a da proteção e da segurança. Esses 
produtos se tornaram um grande filão do mercado nessa era de crise pandêmica, para maior lucratividade dos comerciantes inescrupulosos.

A pretensão arrogante de se poder circular normalmente pelas ruas da cidade sem qualquer tipo de preocupação em relação aos concidadãos, é, na situação excepcional de uma pandemia, um gesto egoísta. Schopenhauer enuncia a sentença lapidar desse tipo de caráter: "Pereça o mundo, mas que eu seja salvo" (E II, 212). Ouso mudar a sentença para a seguinte forma: "Pereça o mundo, mas que eu goze". Na existência ordinária do passado havia um grande estímulo para que vivêssemos intensamente a sociabilidade, os ritos de consumo, as experiências no espaço público, como se somente fôssemos pessoas de valor se porventura exercêssemos os impulsos narcísicos que visam a conquista de prazer, gozo e satisfação. Contudo, essa velha ordem ruiu e a erupção pandêmica exige um novo contrato social na qual renunciamos (esperamos que provisoriamente) à liberdade de ir em vir em prol de uma maior segurança sanitária para todos. Ou seja, urge que o egoísmo (com sua inerente percepção autocentrada da vida) seja domado pelo cidadão, sem dúvida um esforço hercúleo, mas que é fundamental para que as medidas de contenção da COVID-19 surtam efeito satisfatório, ou seja, a diminuição do índice de mortalidade da pandemia. Quem aceita renunciar aos seus hábitos corriqueiros em nome da salvação da sociedade? Conforme argumenta Schopenhauer, "O egoísmo é colossal, ele comanda o mundo. Se fosse dado pois a um indivíduo escolher entre a sua própria aniquilação e a do mundo, nem preciso dizer para onde a maioria se inclinaria" (E II, 121).

O vírus é a grande ameaça fantasmática que amedronta qualquer pessoa de bom senso. Temos a sensação pânica de que ele é uma presença ubíqua de cuja ação pandêmica jamais conseguiremos escapar, apesar de aplicarmos todas as medidas profiláticas sugeridas pelas autoridades sanitárias. Tudo o que é estranho, externo, exterior à nós mesmos e ao nosso lar torna-se uma ameaça mortal da qual devemos nos esquivar. Daí procedimentos que seriam, em condições normais, considerados excêntricos, tornarem-se cada vez mais naturalizados. Nenhum relaxamento é possível. Cuidados redobrados com os fluidos corporais. Talvez o grande problema societário, após a ansiada contenção da COVID-19, seja a sensação de desconfiança que permanecerá entre as pessoas que se preocuparam em se resguardar dos riscos de contágio, minando os traços mais efusivos dos comportamentos cordiais, apertos de mãos, abraços, beijos. Quando poderemos normalizar a realização dos gestos mais afetuosos para com nossos amigos e entes queridos? Qual o prazo seguro para que os contatos corporais sejam novamente consentidos sem os enfadonhos temores de contaminação?

A boa sociabilidade de outrora exigia que mantivéssemos a justa-medida nas relações interpessoais. A solidão excessiva incomoda, a proximidade excessiva irrita. Nem muito próximo nem muito afastado de outrem. Mesmo para algumas pessoas avessas ao convívio social, a "insociável sociabilidade" ${ }_{5}$ sempre foi a base das relações humanas, com suas inerentes contradições e antagonismos axiológicos. Manter a devida distância era imputada como a regra de ouro de uma convivência salutar e um dos fundamentos das boas maneiras. O isolamento social, para pessoas de caráter extrovertido, certamente é um tormento. Mas a força das circunstâncias quebra essa disposição amistosa tão importante para uma sociedade bem integrada, e perseverar nesse regime de reclusão familiar é uma outra forma de demonstração de empatia para com nossos amigos e demais entes queridos que não estão incluídos em nosso círculo doméstico. Por sua vez, para os grupos familiares que estão forçosamente fechados em um espaço, é fundamental que haja da parte de todos mais tolerância, mais paciência e mais capacidade dialógica nessa convivência. Muitas relações

${ }^{5}$ KANT, Ideia de uma história universal de um ponto de vista cosmopolita, 8. 
infelizmente só se tornam mais suportáveis por causa das exigências cotidianas de conciliação entre espaço doméstico e espaço público. Com o isolamento social, pessoas cujas relações familiares são desajustadas apresentam comportamentos irritadiços, virulentos, agressivos, potencializando assim os riscos de ações violentas entre os membros. Casos de feminicídio abundam na vigência da reclusão doméstica, e as próprias circunstâncias precárias impedem maior controle policial sobre essas covardes violências conjugais, aumentando assim a impunidade dos agressores. Se já não basta a angústia da reclusão doméstica e o temor da contaminação, discórdias familiares amplificam ainda mais o sofrimento daqueles que se adequam aos parâmetros epidemiológicos de isolamento social e tornam o organismo, inclusive, mais vulnerável do ponto de vista psicossomático, pelo efeito deletério gerado pelo estresse na diminuição do nível de imunidade corporal. Nessa atual conjuntura pandêmica todo esforço pessoal para se refrear os ímpetos mais discordantes são de grande valia não apenas para nós mesmos enquanto pessoas, mas sobretudo para os familiares com os quais convivemos intensamente cada momento do longo período de isolamento social, inevitável. Amar é também saber dominar impulsos coléricos que prejudicam um convívio familiar mais harmônico.

A grande lição política de uma pandemia é a constatação de que nada serve um indivíduo que não se compreende como membro de uma realidade maior do que o seu próprio eu. O fim da vida humana não é apenas a realização individual, mas a integração pessoal na sociedade, com todas as suas contradições e aborrecimentos inerentes. Não basta que cada indivíduo realize os preceitos epidemiológicos para se evitar o risco de contágio, é também necessário se contar com o compromisso de fulano, beltrano e sicrano nesse grande esforço sanitário. Por isso o cumprimento das diretrizes estabelecidas pelas autoridades médicas e profissionais de saúde é um genuíno exercício de cidadania, solidariedade e moralidade pública. Ética e Política intimamente interligadas. Para Karl Jaspers,

A terapia médica assenta em dois pilares: o conhecimento científico-natural e a humanidade. O médico é o perito que põe à disposição do paciente o seu saber e o seu poder, tratando e, simultaneamente, instruindo-o. O pressuposto é que ambos, médico e paciente, são seres racionais que se opõem conjuntamente a um processo da natureza, conhecendo-o e tratando$\mathrm{o}$, e que pela sua humanidade se unem na apetecibilidade da meta ${ }^{6}$

O grande temor dos empresários e economistas reside na eminente diminuição da produção global em todos os setores, fato irrevogável em cumprimento às exigências das medidas de segurança para a contenção da COVID-19. Muitas funções foram razoavelmente adequadas para o home office, mantendo assim a normalidade superficial de um problema onipresente para toda a humanidade. O imperativo ideológico do produtivismo não se cala no longo período de isolamento social no qual estamos submetidos. É salutar que tentemos manter um mínimo da rotina de outrora e adaptemos nossas atividades laborais no espaço doméstico, porém, devemos compreender que não estamos em uma calamidade social decorrente da falta de abastamento de água ou de problemas de transporte público. Tornase muito árduo manter um padrão de comportamento empreendedor, resiliente, empenhado, diante das restrições societárias impostas pelo confinamento em casa, pois não apenas familiares e entes queridos sofrem, alguns mais, outros menos, dos efeitos da COVID-19, mas também a miríade de desconhecidos cujas desventuras são relatadas diariamente nos meios de comunicação e de cujos casos convêm que tomemos conhecimento, para que tenhamos uma dimensão ampla dos transtornos humanitários. Para

${ }^{6}$ JASPERS, O médico na era da técnica, 19. 
algumas pessoas a experiência do isolamento social pode ser pertinente para o desenvolvimento de alguns projetos que exigem tempo livre ou concentração, pode ser também um momento para organização da vida privada. Todavia, nem todas as pessoas ao redor do mundo conseguem fazer do confinamento doméstico uma possibilidade agradável, e tal enfado deve ser respeitado. Há famílias economicamente precárias que vivenciam o isolamento social como uma experiência-limite, e a demora governamental em conceder o suporte financeiro para remediar a perda de renda potencializa ainda mais a ansiedade dessas pessoas. Por isso a decisão de suspensão, por tempo indeterminado, das atividades pedagógicas das universidades públicas é plenamente acertada. Professores e alunos, na medida do possível, conseguem manter uma disciplina de pesquisa, leitura e estudos em suas casas, o que é bastante viável intelectualmente, mas sem maiores compromissos institucionais e sem as estressantes exigências de avaliação ou cumprimento das normas técnicas. Estudar não afasta, todavia, o temor do contágio e o medo da morte. É importante mobilizarmos tanto o corpo docente como o corpo discente no período de isolamento social decorrente das medidas de precaução contra a COVID-19, contudo, precisamos levar em consideração que estamos vivendo um período de elevada letalidade, circunstância que gera traumas em toda a sociedade consciente do trágico momento em que vivemos. Não obstante o caráter altamente positivo do conhecimento partilhado nas experiências didáticas, não estamos em um momento de desempenhar atividades que exijam compromissos acadêmicos rigorosos.

As classes reacionárias, adoradoras das benesses materiais proporcionadas pelo poder financeiro, empreendem meios de desestabilizar os esforços técnicos de isolamento social, pois não conseguem viver sem que haja pessoas para lhes servir e ocultam essas inclinações patriarcais em nome de uma liberdade abstrata, a de "se fazer o que se quer". Mas, "o que é fazer o que se quer" se nem mesmo sabemos se há um sujeito por detrás do querer? Essa chusma narcisista defende uma intepretação distorcida de liberalismo social que, em sua origem filosófica, pressupõe autonomia do indivíduo, isto é, capacidade de deliberar, decidir e escolher sem qualquer coerção externa, sem se pautar em causas inadequadas que obnubilam o discernimento. As elites rapinantes e os grupos que aspiram alcançar o seu status social são, na verdade, mentalidades conservadoras contrárias ao desenvolvimento social, que dependem da miséria das massas para que possam viver satisfatoriamente com todos os seus privilégios institucionais. Esses segmentos penas reagem sordidamente aos movimentos emancipatórios das massas, capitaneando todos os recursos, legais e ilegais, para frear as políticas públicas e os projetos institucionais por mais direitos constitucionais e por mais igualdade social.

\section{Pandemia e Controle Social}

A pandemia é um grande ensaio político para a ampliação das medidas de controle social. Aferição da temperatura corporal de viajantes para que se detecte algum sinal de febre, monitoramento de aparelhos celulares para que se cerceie a mobilidade social dos indivíduos, talvez até mesmo fiscalização do fluxo de mensagens dos aplicativos, e-mails e redes sociais. Um panóptico do corpo e da mente que impõe uma rotina disciplinar na vida pessoal. A aplicação de protocolos assépticos essenciais e a manutenção constante de procedimentos higiênicos nos exige atenção contínua para que nenhum deslize coloque em risco todo um esforço sanitário de controle epidemiológico. Importante também ressaltar que a violação de nossa privacidade e o monitoramento íntimo das nossas condições 
orgânicas, outrora tão desprezada pelo senso liberal de vida, tornam-se exigências cada vez mais inquestionáveis, ainda que tenhamos bastante dificuldade em aceitá-las e incorporá-las em nosso modus vivendi.

Em cidades cujas populações são mais desleixadas com as medidas de isolamento social, autoridades governamentais estabelecem toque de recolher. Tal é o preço de uma luta pública eficaz contra a devastação pandêmica, pois os caprichos egoístas e a profusão social da ignorância são perigos para a ordem pública. O bem comum deve sempre estar acima das contingências individuais quando estas visam apenas causar discórdias, desinformação e pânico entre as pessoas. Fronteiras internacionais fechadas até segunda ordem e formação de cordões sanitários entre as cidades, procedimentos que, em uma situação política normal, se caracterizam como ações xenofóbicas e excludentes, se tornam meios fundamentais para a contenção da COVID-19. O espírito cosmopolita do turismo está assim suspenso, o que não significa que menosprezemos as maravilhas do resto do mundo. Obviamente que as medidas restritivas de circulação humana são bastante favoráveis aos desmandos despóticos de governantes autoritários que, em nome dos procedimentos epidemiológicos de exceção, oportunamente se aproveitam da crise pandêmica e assim aplicam medidas repressivas contra a sociedade. Porém, não deixa de ser curioso que tanto o presidente ungido pela miséria do fascismo e notório adorador de torturadores, como os seus seguidores acéfalos apoiadores de intervenção militar, se manifestem contrariamente aos métodos científicos do isolamento social e suas inerentes técnicas assépticas, considerando-as abuso de autoridade e violação da liberdade civil. Esses segmentos antidemocráticos se irritam com as determinações limitadoras da circulação social, mas sonham com a suspensão de todas as garantias constitucionais e instituições democráticas que protegem os indivíduos do arbítrio governamental. A direita xucra defende apenas a "democracia" que lhe convém, isto é, a "democracia" do mercado, dos banqueiros, dos grandes varejistas, regime gerencialista que não apenas espolia a massa trabalhadora cada vez mais precária e desprovida de direitos legais, mas que prospera economicamente com o adoecimento e morte dos seus funcionários. O bom trabalhador, dócil e submisso, deve aceitar condições insalubres para se tornar rentável na grande era de desajuste laboral. Caso o empregado morra infectado pela COVID-19, mero acidente logístico. Outro trabalhador poderá substituir o posto vago.

Situações graves ocorrem em sociedades com déficit democrático, onde pessoas que apresentam os sintomas da COVID-19 são hostilizadas e expulsas das suas casas, tal como portadoras das forças maléficas que contaminam a ordem comunitária. A mesma disposição se aplica aos bodes expiatórios eleitos para que se possa culpá-los pelos transtornos da pandemia, de modo a se livrar governos ineptos dos seus crimes de responsabilidade. Os chineses, conforme a narrativa odienta de demagogos, ideólogos idiotas e charlatões religiosos da direita xucra, promoveram uma conspiração global para a tomada do poder mundial e a inerente aniquilação da economia liberal. A pandemia da COVID-19, segundo a insanidade direitista, faz parte de um grande projeto comunista para controlar o mundo através da desestabilização econômica do capitalismo. Essa infame direita xucra tentou de todas as formas mascarar a gravidade da COVID-19 perante o seu rebanho de seguidores, afirmando, mentirosamente, que essa pandemia que nos aflige possui letalidade menor do que outras doenças do passado. Uma gripezinha que, segundo o presidente energúmeno, não afeta pessoas com porte atlético. Esses negacionistas, exímios inimigos da ciência que se empenham para desmerecê-la perante o obscurantismo ideológico e a fé cega não hesitam em recorrer aos seus frutos quando se encontram com problemas de saúde. Os ladrões da fé vendem suas bençãos curativas para o rebanho, mas se internam em hospitais de ponta quando necessário, são tratados não com orações falsas, mas com medicina, ciência, razão, técnica, remédios, operacionalizadas pelas hábeis mãos dos profissionais de saúde. 
Na mentalidade sociopata dessa chusma asquerosa, toda a sociedade deve romper o isolamento social e retornar novamente ao trabalho, para maior satisfação da economia, isto é, dos patrões, que estão devidamente protegidos dos efeitos da COVID-19 nos seus bunkers, condomínios de luxo, mansões, sítios e até mesmo portentosos iates. Essa elite autocentrada vocifera de sua asséptica e confortável zona de conforto contra o isolamento social e a diminuição do fluxo produtivo. Os trabalhadores sempre são a grande bucha de canhão de um regime capitalista desregulado. Para que o ritmo laboral possa ser retomado, as lideranças políticas que somente gerenciam a coisa pública conforme critérios de rentabilidade econômica pró-patronato apregoam sem comprovações técnicas rigorosas panaceias que resolverão o problema dos efeitos da COVID-19 nos infectados, de modo a se justificar, assim, a suspensão do isolamento social. Para os trabalhadores infectados, cloroquina, o apregoado remédio salvífico, sem qualquer embasamento científico. Enquanto isso, os pastores oportunistas que afirmavam curar pela fé todas as doenças, não conseguiram curar nenhuma pessoa contaminada pela COVID-19. O grande medo da plutocracia capitalista reside na iminência da suspensão total da produção em favor da conservação das vidas dos trabalhadores de base. Uma sociedade totalmente paralisada e confinada em casa.

\section{Transformações radicais do modo de viver}

A tragicidade de uma pandemia reside na impossibilidade da participação da despedida dos moribundos. A solidão dos últimos momentos, vivenciados, usualmente, inconscientemente, pois o corpo se encontra sedado e entubado para que a última tentativa de salvar a vida tenha efeito. Ritos funerários cumpridos apressadamente para se evitar qualquer tipo de contaminação. Muitas vezes os moribundos sequer recebem os últimos sacramentos. Cemitérios expandem vertiginosamente sua capacidade de recepção dos corpos, em um tétrico planejamento logístico para se evitar situações impronunciáveis. Corpos sepultados de maneira indistinta por questão de economia de espaço e por precauções sanitárias. Trata-se assim da supressão violenta de todo simbolismo sagrado. A hora da morte se torna um mero fenômeno biológico, asséptico e burocrático. Norbert Elias argumenta que

A morte é um dos grandes perigos biossociais na vida humana. Como outros aspectos animais, a morte, tanto como processo como imagem mnemônica, é empurrada mais e mais para os bastidores da vida social durante o impulso civilizador. Para os próprios moribundos, isso significa que eles também são empurrados para os bastidores, são isolados. ${ }^{7}$

Tamanha calamidade humanitária nos faz repensar o valor da vida, nossos critérios axiológicos, nossas inquietações existenciais. Projetos pessoais extintos para sempre, permanecendo a dor, o vazio, o luto e o sofrimento para os que ficam. Por isso toda pessoa que adota postura irresponsável em relação aos devidos cuidados epidemiológicos para a prevenção da COVID-19, toda pessoa que tripudia da seriedade dessa questão e do seu efeito terrível para o bem-estar da humanidade blasfema contra a honra dos mortos. Segundo Gadamer, "É precisamente no tratamento do doente crônico e, por fim, no acompanhamento do moribundo que voltamos sempre a ser lembrados que o paciente é uma pessoa e não um "caso". ${ }^{8}$

\footnotetext{
7 ELIAS, A solidão dos moribundos, 19.
}

${ }^{8}$ GADAMER, O caráter oculto da saúde, 106. 
As privações decorrentes de um longo período de isolamento social, a diminuição da produção de bens de consumo (úteis ou supérfluos) e os problemas de oferta de serviços exige de cada indivíduo uma reconfiguração dos seus costumes prosaicos. Para muitas pessoas a experiência de um isolamento social empreendida para se conter a curva de contágio da pandemia é chocante, não apenas pelas vidas alheias perdidas, mas também pela impossibilidade de se satisfazer os desejos ordinários. É risível o anseio de se manter, na vigência do isolamento social, hábitos da dita vida normalizada. São pessoas despreparadas para uma calamidade pública de exceção, incapazes de compreender que estamos nessa situação sem escapatória imediata. Gastronomia é sempre pertinente em condições razoáveis da ordem pública, mas se as carências materiais impostas pelo isolamento social e agravadas pelo desabastecimento de produtos nos mercados impedem que apliquemos o requinte culinário, cabe a ponderação sobre qual o bem mais valioso.

O aprendizado moral que o isolamento social impõe ao sujeito narcísico é a urgência de se adotar positivamente disposições mais sustentáveis, mais frugais, mais parcimoniosas em relação ao dispêndio de recursos materiais. Poupar mais e gastar menos. A afluência da sociedade de consumo forjou uma civilização hedonista incapaz de lidar com privações materiais e usualmente desperdiçadora de gêneros fundamentais para a boa subsistência humana. Talvez a calamidade pandêmica estimule uma maior quantidade de pessoas a desenvolver maior compromisso social com o uso dos bens disponíveis, a despeito de todo chamariz publicitário que incentiva a satisfação plena do gozo e um sistema industrial regido pela obsolescência das coisas. A mídia, com seu apelo sensacionalista para mobilizar a opinião pública e mantê-la em estado constante de tensão, enuncia o slogan "guerra contra o coronavírus". São fundamentais mais e mais esforços pessoais para que os efeitos da COVID-19 sejam atenuados, decorrendo daí o apelo ao conceito de "guerra". Contudo, para muitas pessoas outrora acomodadas ao modo de vida aburguesado, a menor privação material é vivida como um vale de lágrimas, uma tristeza depressiva. Gerações anteriores em tempos de guerra manifestaram muito mais bravura, resiliência e senso de responsabilidade diante das adversidades concretas, adotando práticas e hábitos alimentares pouco usuais em nome da sobrevivência. Povos que viveram sob bombardeio intermitente das tropas inimigas souberam resistir com muito mais gana do que muitas famílias ansiosas em retornar ao ritmo comum da vida capitalista de desejo, consumo, gozo, satisfação.

É justamente a recessão econômica derivada da diminuição do processo ordinário de consumo que gera na casta empresarial o ressentimento contra as medidas sanitárias de isolamento social. Para minar os heroicos esforços epidemiológicos dispendidos na contenção da COVID-19, segmentos empresariais avessos aos mais básicos direitos humanos exercem intenso lobby junto aos parlamentares e aos poderes executivos para que as prescrições de isolamento social sejam suspensas, e assim o povo circule nas ruas sem qualquer impedimento. Hordas assassinas de empresários realizam carreatas da morte para protestar contra o fechamento do comércio e vociferam contra as medidas epidemiológicas de isolamento social, exigindo liberdade econômica quando na verdade bradam o infame "morte à vida" tão caro aos fascistas. A cada dia constatamos exemplos deploráveis da maleficência empresarial que trata seus empregados como escravos e lhes impõe todo tipo de humilhação. Essa elite rapinante não manifesta qualquer empatia para com a sociedade, apenas visa aumentar sordidamente os seus índices de lucratividade, mesmo que para isso seja necessário que multidões se aglomerem nas vias públicas, nos meios de transporte, no comércio e nos postos de trabalho, arriscando-se ao contágio pela COVID-19 para que não deixem a lógica do mercado definhar. Essa sanha capitalista é a expressão mais pura da economia necropolítica, pois é uma prosperidade imediatista e tacanha que nasce da morte de inúmeros seres humanos desprovidos de valor substantivo conforme as diretrizes de uma 
ideologia sufocante orientada para consolidar o poder financeiro de um seleto grupo de empresários, acionistas e corporações. Os plutocratas travestidos de patriotas apregoam que há coisas mais importantes do que viver, tal como preservar a grandeza do país para os descendentes, escondem suas sinceras intenções, isto é, salvar o mercado da devastação, pois essa é única meta econômica realmente importante para tais segmentos desprovidos de qualquer senso de responsabilidade social. Alegam que ninguém quer morrer, mas que todos nós devemos correr riscos e fazer o país voltar ao pleno funcionamento produtivo, ou seja, a ordem do mercado não pode ser prejudicada infinitamente. Trabalhadores assalariados se arriscam e morrem enquanto os plutocratas se salvam. A Bolsa de Valores amplia os seus índices de rentabilidade com as mortes dos seres humanos, pois quanto mais cidadãos mortos menos gastos públicos são dispendidos, e os que sobrevivem, em uma economia colapsada, aceitam perder direitos em nome de mais empregos, precários.

A solução postulada pelo ultraliberalismo para sanar o déficit fiscal originado pelo imprescindível investimento público para atenuar os estragos humanitários oriundos da COVID-19 é: privatizar, privatizar tudo. Essa aberrante posição não denota incompreensão do problema que assola a sociedade; trata-se, antes, de um projeto entranhado na gestão política ao serviço do grande capital, inimigo da coisa pública. A devastação pandêmica é uma grande oportunidade para que a plutocracia ultraliberal também imponha sua devastação econômica sobre a sociedade. Os gastos públicos efetivados para enfrentar a COVID-19 desagradam os adeptos do fascismo de mercado, que pretendiam relegar ao esquecimento aqueles que não encontram recursos para sobreviver. Tudo para a elite, nada para a população.

\section{Solidariedade Pessoal e Responsabilidade Empresarial}

Em toda situação de calamidade pública afloram não apenas casos de barbárie, mas também de magnitude humana. Ações sublimes de solidariedade e de caridade de indivíduos e de organizações comprometidas com o bem-estar da sociedade fortalecem o ânimo de toda pessoa de boa vontade que aspira contribuir com a diminuição do sofrimento dos enfermos e daqueles que são afetados pelo flagelo pandêmico. Schopenhauer argumenta que "O bom caráter apelará para a assistência de outrem com tanta ou mais confiança quanto mais ele estiver consciente da sua prontidão para prestar-lhe a sua” ( E II, 220-221). Porém, horresco referens, a gravidade da situação pandêmica não nos permite investigar os motivos morais dessas ações benevolentes, o que importa é o resultado concreto, seja o conforto final para os moribundos, seja a distribuição de alimentos para as pessoas carentes que estão confinadas em suas casas, seja os cuidados paliativos com aqueles que dormem ao relento e estão sujeitas aos efeitos mais duros do contágio da COVID-19. Não se trata de uma crua ponderação pragmática, mas o reconhecimento de que boas intenções sem obras não são suficientes e condenam as seráficas almas ao naufrágio social. É evidente, todavia, que ações solidárias nascidas de disposições efetivamente altruístas são moralmente muito mais nobres, e seria o ideal que todos esforços empreendidos para diminuir ao máximo as perdas humanas decorrentes da COVID-19 nascessem da mais pura filantropia. No caso de cidadãos comuns, os inúmeros casos de atos benevolentes para ajudar pessoas afetadas direta ou indiretamente pelos transtornos da COVID-19 certamente brotam do espírito de generosidade que permeia a disposição de ânimo de tais agentes, e somente se usarmos a Luneta do Mal de Simplício poderíamos cogitar a existência de interesses ocultos nessas 
ações. Quem sabe se as ações solidárias não visem imediatamente o bem-estar dos receptores das dádivas, mas o achatamento da curva da COVID-19, de modo que pessoas com dificuldades financeiras não necessitem obter sustento trabalhando e assim se arriscando ao contágio, o que ocasionaria ainda mais transtornos sociais. Contudo, conforme dito linhas atrás, em uma emergência sanitária, é espúria qualquer especulação sobre o fundamento moral das ações, não importa se estas nascem da compaixão, do cumprimento do formalismo do dever, do sentimento republicano de participação na esfera pública ou de um cálculo utilitário. Já empresas que jamais apresentaram procedimentos deontologicamente sustentáveis se tornam os baluartes do compromisso público para com a sociedade através de doações milionárias, certamente confiando que esses gestos extraordinários, amplamente divulgados pela mídia, lhes renderão polpudos dividendos futuros. Por isso devemos nos precaver em relação ao fetiche da responsabilidade empresarial, pois as mesmas corporações que espoliam trabalhadores e esgotam as condições naturais da biosfera são as que também despontam espetacularmente como a salvaguarda financeira do mundo em crise pandêmica. Não podemos acreditar que bancos, conglomerados empresariais e outros sócios plutocráticos, pouco afeitos aos parâmetros democráticos e ao bem comum, pretendam contribuir para o enfrentamento dos estragos da COVID-19 apenas pelo amor à humanidade. Compensações fiscais e fortalecimento da imagem mercadológica das marcas corporativas estão por trás das "benevolentes" uniões empresariais. No entanto, dinheiro não tem cheiro e o suporte monetário das empresas que apoiam os esforços governamentais para o controle da COVID-19 será bastante conveniente para a reconstrução da infraestrutura social após a superação do grande pico de estagnação produtiva. Uma saída para essa aporia deontológica consistiria na elevação da taxa de tributação que as grandes empresas deveriam pagar aos cofres públicos, para que tais corporações cumprissem suas obrigações sociais não através de dádivas benevolentes que talvez exijam compensações econômico-políticas futuras, mas sim pelo pagamento dos impostos devidos, muitas vezes sonegados descaradamente.

\section{As forças necrófilas desnudadas pela COVID-19}

No submundo do fascismo de mercado, quais são os grupos contrários ao isolamento social? Os pastores de seitas fundamentalistas, que dependem da espoliação dos dízimos dos fiéis ignorantes para que possam enriquecer ilicitamente, e os milicianos, que em regiões controladas por essas máfias obrigam comerciantes a abrirem os seus estabelecimentos a despeito de toda determinação oficial contrária, de modo a cobrarem suas propinas (e mesmo que os comerciantes não sigam suas ordens ilegais ainda assim essa súcia armada faz ainda assim suas cobranças criminosas, deixando os comerciantes em situação de risco de qualquer forma) Essas duas categorias necrófagas são parasitas sociais inimigas das classes trabalhadoras e servem de força bruta para o cimento bolsonarista. Qualquer sociedade democrática, não importa o seu espectro político, deve se empenhar em enfrentar corajosamente essa escória que tanto atenta contra a esfera pública e o saudável ordenamento social. Os pastores-crápulas, por suas interpretações distorcidas dos Evangelhos, colocando-se como lideranças contrárias aos paradigmas laicos da sociedade moderna e seus fundamentos republicanos; os milicianos, por sua atuação como poder 
paralelo em relação ao Estado (ainda que seus governantes, quando controlado pela plutocracia capitalista, usa convenientemente do terror desses grupos mafiosos para impor suas determinações ao resto da sociedade civil, acuada pelo medo da morte). Por isso entre essas igrejas degradadas e as milícias há uma simbiose extraordinária, na figura do miliciano cristão, que tão bem realiza o papel de executor da necropolítica do modo mais eficiente para os grandes gestores da pirataria capitalista.

Tanto no Brasil como no resto do mundo a extrema-direita habilmente manipula a opinião pública com sua rede organizada de desinformação, cumprindo assim sua agenda política obscurantista de amedrontamento de segmentos sociais intelectualmente ignorantes e desprovidos de capital cultural, independentemente de seu poder aquisitivo. Teorias conspiratórias delirantes, discursos paranoicos de lideranças partidárias e outros procedimentos escusos sustentam sua grande teia ideológica. $\mathrm{O}$ negacionismo fundamenta sua visão de mundo e ações práticas promotoras de desastres sociais. O mais puro regime da pós-verdade se manifesta aqui, pois nada mais é confiável, preciso, claro. Com a perda dos referenciais epistemológicos da verdade, ocorre, por conseguinte, o descrédito em relação às atividades científicas, que só possuem validade e legitimidade, de acordo com os mandamentos da extrema-direita, quando as prescrições dos especialistas ratificam os caprichos irracionalistas do condutor do povo, o presidente ungido pelas mãos dos pastoresempresários. Orientações impessoais e dados técnicos são desprezados quando não agradam às inclinações narcísicas do grande idiota útil das forças ocultas que coordenam um mercado desumano e alheio ao bem comum. Autoridades médicas são achincalhadas com a anuência do vírus presidencial, apenas comprometido com a satisfação dos seus apoiadores embrutecidos. A crença cega no mito político é a culminação do desprezo à razão, a redução ao nada da própria razão. Por isso adeptos da extrema-direita, bombardeados com uma série de informações heteróclitas e cognitivamente inverossímeis replicadas em redes sociais e aplicativos, acreditam piamente nas sandices mais horrendas produzidas pelo gabinete de ódio. Mesmo que as mentiras políticas sejam desmitificadas, a horda irracional e iracunda da direita xucra jamais deixará de acreditar no teor epistemológico das emissões que ratificam o projeto niilista de Bolsonaro, em nosso infeliz quadro político alheio aos princípios democráticos. Essa chusma feroz, chorume político, depende da polarização com o grande inimigo para consolidar a sua própria identidade partidária. São os afetos tristes que impulsionam suas atividades e percepções da realidade, um ressentimento impotente que é mascarado com gestos brutais, agressividade, retórica virulenta e apelo machista ao armamentismo e ao militarismo como forma de velar sua sexualidade reprimida e fracassada. Esqueçamos a patuscada de "Brasil acima de tudo, Deus acima de todos". Na verdade, o desgoverno Bolsonaro pauta sua gestão sob o lema "Morte acima de tudo", com a variante "Morte à Vida". O falso messias Bolsonaro não veio trazer vida, mas sim morte em abundância para todo o povo brasileiro, em especial para os mais pobres, para os quilombolas, os favelados, os povos indígenas. Sua virulência ideológica cada vez mais mata a coisa pública brasileira.

Na ausência de projetos efetivos para o fortalecimento da democracia social, a horda direitista apenas vitupera contra os seus opositores, identificando-os todos como "comunistas" que aspiram quebrar a economia para que a lógica do mercado capitalista seja destruída. Uma pandemia não possui espectro político, mas quando um governo genocida 
desinforma a população e realiza atos coordenados para prejudicar os cuidados profiláticos necessários para enfrentar as mazelas socio-sanitárias e atenta contra as instituições republicanas, visualizamos dois campos antagônicos incomunicáveis: a democracia, associada ao princípio da vida, e o nazifascismo, irmanado com a necrofilia. Qualquer governança que coloque a ideologia e os interesses do mercado acima da salvação da sociedade é inimiga da humanidade.

\section{Considerações Finais}

Todo respeito e reconhecimento pelo trabalho de médicos, enfermeiros, prestadores de serviço de limpeza, profissionais de saúde e cientistas envolvidos na contenção do coronavírus e na busca por uma cura para esse mal. A solução de toda doença requer razão, ciência, técnica, conhecimento, competência, planejamento sanitário. Qualquer outra categoria deve apenas ser valorizada no foro privado, sem qualquer promiscuidade com as políticas públicas que estão na linha de frente para o tratamento da pandemia na vida das pessoas. Toda força sociopolítica alheia ao bem comum não merece qualquer crédito na luta humana pela superação dos efeitos devastadores da COVID-19. Por isso é fundamental não apenas o apoio incondicional aos órgãos responsáveis pela contenção da pandemia, como também nos fiarmos apenas nas informações oficiais emitidas por autoridades competentes, e não em personalidades irresponsáveis que prosperam politicamente mediante o caos social. Qualquer posição contrária aos critérios técnicos e científicos corre o risco de favorecer a fermentação de ideologias necrófilas e a desinformação social. Trata-se de uma grande crise mundial que não será superada sem engajamento e solidariedade de todas as partes, daí se concretizando a necessidade de cumprimento de procedimentos epidemiológicos que brotam de uma perspectiva ética que pressupõe a sociedade como a estrutura fundamental da existência, para além de toda idiotia política ou egocentrismo.

\section{Referências}

DYSON, F. O Sol, o Genoma e a Internet: ferramentas das revoluções científicas. Trad. de Otacílio Nunes Jr. São Paulo: Companhia das Letras, 2001.

ELIAS, N. A solidão dos moribundos. Trad. de Plínio Dentzien. Rio de Janeiro: Jorge Zahar, 2011.

GADAMER, H-G. O caráter oculto da saúde. Trad. de Antônio Luz Costa. Petrópolis: Vozes, 2006.

JASPERS, K. O médico na era da técnica. Trad. de João Tiago Proença. Lisboa: Edições 7o, 1998.

KANT, I. Ideia de uma história universal de um ponto de vista cosmopolita. Tradução de Rodrigo Naves e Ricardo Ribeiro Terra. São Paulo: Martins Fontes, 2003.

SCHOPENHAUER, A. Sobre o Fundamento da Moral. Trad. de Maria Lúcia Mello Oliveira Cacciola. São Paulo: Martins Fontes. 2001.

SONTAG, S. A doença como metáfora. Trad. de Márcio Ramalho. Rio de Janeiro: Graal, 2002. 
16 | Pandemia, engajamento sanitário, desajuste social e necrofilia presidencial

TODOROV, T. Os inimigos íntimos da Democracia. Trad. de Joana Angélica d'Ávila Melo. São Paulo: Companhia das Letras, 2012. 